\title{
GEOPROCESSAMENTO E CARTOGRAFIA GEOMORFOLÓGICA: EXPERIÊNCIAS NA REGIÃO DOS GRANDES ESCARPAMENTOS DA ZONA DA MATA MINEIRA
}

\author{
Derik Ribeiro de Paiva \\ Universidade Federal de Juiz de Fora, MG, Brasil. \\ geoderik@gmail.com \\ Roberto Marques Neto \\ Universidade Federal de Juiz de Fora, MG, Brasil. \\ roberto.marques@ufjf.edu.br
}

\begin{abstract}
RESUMO
A cartografia vem sendo cada vez mais empregada enquanto arcabouço metodológico tanto para estudos voltados para a análise e compreensão das dinâmicas e processos responsáveis pelo engendramento dos distintos tipos de modelados de relevo, quanto como suporte ao planejamento. Nesse contexto, a presente comunicação tem como fito a elucidação acerca de como o geoprocessamento e as geotecnologias se inserem na rotina do trato cartográfico do relevo, a partir de uma experiência levada a efeito nas imediações do município de Goianá (MG). Como metodologia para classificação das formas de relevo partiu-se do quarto nível categórico, da proposta elaborada no âmbito do Instituto Brasileiro de Geografia e Estatística, cujo princípio básico trata-se da ordenação dos fatos geomorfológicos conforme uma classificação que leva em consideração aspectos temporais e espaciais, e que viabiliza a distinção dos modelados como unidade básica do relevo, bem como os grupamentos que mantém relações hierárquicas com essas unidades básicas. A referida metodologia, viabilizou a elaboração de uma carta geomorfológica condizente com os aspectos do relevo regional, e que possibilita embasamento para o planejamento na região em suas distintas esferas de atuação, demonstrando a eficácia e relevância do geoprocessamento na confecção de documentos cartográficos que espacializam as formas do relevo.
\end{abstract}

Palavras Chaves: Cartografia do Relevo. Cartografia Digital. Morfogênese.

\section{GEOPROCESSING AND GEOMORPHOLOGICAL CARTOGRAPHY: EXPERIENCES IN THE GREAT ESCARPMENTS REGION OF THE ZONA DA MATA MINEIRA} \begin{abstract}
Cartography has been increasingly used as a methodological framework for studies aimed at analyzing and understanding the dynamics and processes responsible for the creation of different types of relief models, as well as planning support. In this context, this communication aims to elucidate how geoprocessing and geotechnologies are inserted in the routine of the cartographic treatment of the relief, from an experience carried out in the vicinity of the municipality of Goianá (MG). As a methodology for the classification of landforms, the fourth categorical level of the proposal elaborated within the scope of the Brazilian Institute of Geography and Statistics was started, whose basic principle is the ordering of geomorphological facts according to a classification that takes into account temporal and spatial aspects. , and that makes possible the distinction of the modeled ones as basic unit of the relief, as well as the groups that maintain hierarchical relations with these basic units. The referred methodology, made possible the elaboration of a geomorphological chart consistent with the aspects of the regional relief, which provides a basis for planning in the region in its different spheres of activity, demonstrating the effectiveness and relevance of geoprocessing in the making of cartographic documents that spatialize the shapes relief.
\end{abstract}

KEYWORDS: Relief Cartography. Digital Cartography. Morphogenesis

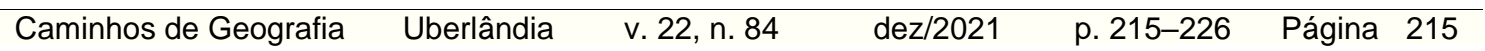




\section{INTRODUÇÃO}

A cartografia constitui-se em uma ferramenta substancialmente importante para as ciências em geral, em especial para as ciências da Terra, uma vez que viabiliza a representação do espaço e das complexas e diversificadas variáveis que integram a superfície terrestre. Quando aplicada ao trato com o relevo, conforme enfatizado por Tricart (1965), permite o enfoque em distintas perspectivas, estas variando de acordo com os objetivos vislumbrados pelo pesquisador, sendo o mapa geomorfológico à base da pesquisa e não simplesmente o produto gráfico final da mesma. $O$ categorizado geomorfológo francês atenta ainda para alguns aspectos técnicos imprescindíveis para a composição do plano de informações desse tipo de documento cartográfico, que contém elementos morfológicos, morfogenéticos, morfométricos, morfoestruturais, morfodinâmicos e morfocronológicos.

No âmbito da Geomorfologia, a cartografia do relevo vem sendo cada vez mais empregada enquanto arcabouço metodológico tanto para estudos voltados para a análise e compreensão das dinâmicas e processos responsáveis por engendrar os distintos tipos de modelados de relevo, quanto como suporte ao planejamento. Uma breve apreciação histórica acerca da evolução da cartografia geomorfológica permite apreender que, no Brasil e no mundo, apesar de padecer de uma falta de isonomia no que tange às metodologias de discernimento e classificação das formas do relevo, o que corrobora em uma dificuldade em se estabelecer estudos comparativos entre os produtos cartográficos gerados, esse campo da geomorfologia a partir da década de 1950 tem sido objeto de interesse de distintas escolas do pensamento científico (COLTRINARI, 2011).

A crescente atenção facultada às técnicas e metodologias de mapeamento geomorfológico se dá no bojo de um contexto histórico no qual as sociedades humanas começam a lograr substanciais avanços tecnológicos no campo da ciência da computação. Segundo Câmara et. al. (1996), com intuito de reduzir os custos de produção e atualização de mapas, no início da década de cinquenta houve os primeiros esforços visando a automatização do processamento de dados georreferenciados. Posteriormente, já na década de 1970, conforme elucidado por Rodrigues (2010), a partir da difusão do uso de microcomputadores a ciência cartográfica passa a concentrar efetiva atenção na automação do desenho, incorporando em seu rol de metodologias e técnicas as oriundas do geoprocessamento. Nesse contexto, há que se destacar o papel importante dos avanços tecnológicos referentes ao processamento de informações geográficas proporcionadas pelo surgimento de diversos e sofisticados softwares e hardwares, que viabilizam a integração de informação alfanumérica com informações gráficas acerca de determinado contexto ambiental, dando aporte a um avanço em direção a uma cartografia digital.

Sobre os avanços no setor tecnológico aqui em voga, Florenzano (2008) destaca os viabilizados pelos sensores remotos, como, por exemplo, os dados topográficos orbitais de radar obtidos pela missão SRTM (Shuttle Radar Topographic Mission). Segundo a autora, a melhor resolução dos dados obtidos pelas vias mencionadas possibilita a mensuração, mapeamento e estudo de uma plêiade de fenômenos geomorfológicos e ambientais, com precisão e agilidade dificilmente alcançável através de das técnicas cartográficas tradicionais. A mesma enfatiza ainda a facilidade de integração dos dados oriundos de sensores remotos com os aventados a partir de outras fontes, possibilitada pelo uso dos Sistemas de Informação Geográfica, ressaltando suas respectivas importâncias para o desenvolvimento das ciências da Terra e ambientais, ao passo que facilitam a inter-relação entre elas. Como consequência desses avanços tecnológicos, tem-se a ampla difusão no meio científico da utilização do Sensoriamento Remoto, que permite inventários mais precisos e abrangentes de informações acerca de determinado local sem que se tenha efetivo contato físico com o mesmo. $\mathrm{Na}$ mesma linha, conforme anteriormente mencionado, o Geoprocessamento viabiliza distintas técnicas de tratamento e manipulação de dados geográficos.

Dessa forma, frente à florescente demanda por documentos cartográficos que subsidiem os processos de intervenção no relevo, emerge uma salutar necessidade por parte dos pesquisadores que atuam na área de estar sempre atentos ao domínio de tecnologias e metodologias que possam aprimorar o processo de cartografação das organizações geomorfológicas nas variadas escalas de análise intrínsecas à Geomorfologia. Nesse contexto, a presente comunicação tem como fito a elucidação acerca de como o geoprocessamento e as geotecnologias se inserem na rotina do trato cartográfico do relevo, suas potencialidades e restrições, ponderadas a partir de uma experiência com a cartografia do relevo levada a efeito nas imediações do município de Goianá localizado, conforme ilustra a Figura 1, na microrregião de Juiz de Fora, na Zona da Mata Mineira, predominantemente sob

$\begin{array}{llllll}\text { Caminhos de Geografia } & \text { Uberlândia - MG } & \text { v. 22, n. } 84 & \text { dez/2021 } & \text { p. 215-226 } & \text { Página } 216\end{array}$


litologias associadas ao Complexo Juiz de Fora (PINTO e SILVA, 2014). Associada aos aspectos climáticos, essa base estrutural apresenta considerável influência nas características do relevo em seus aspectos genético-evolutivos e dinâmicos, fazendo da área abarcada pelo presente mapeamento um demonstrativo do contexto geormofológico regional apresentado no âmbito da bacia hidrográfica do rio Novo, a qual a mesma se insere.

Figura 1- Localização e aspectos geológicos da área mapeada.

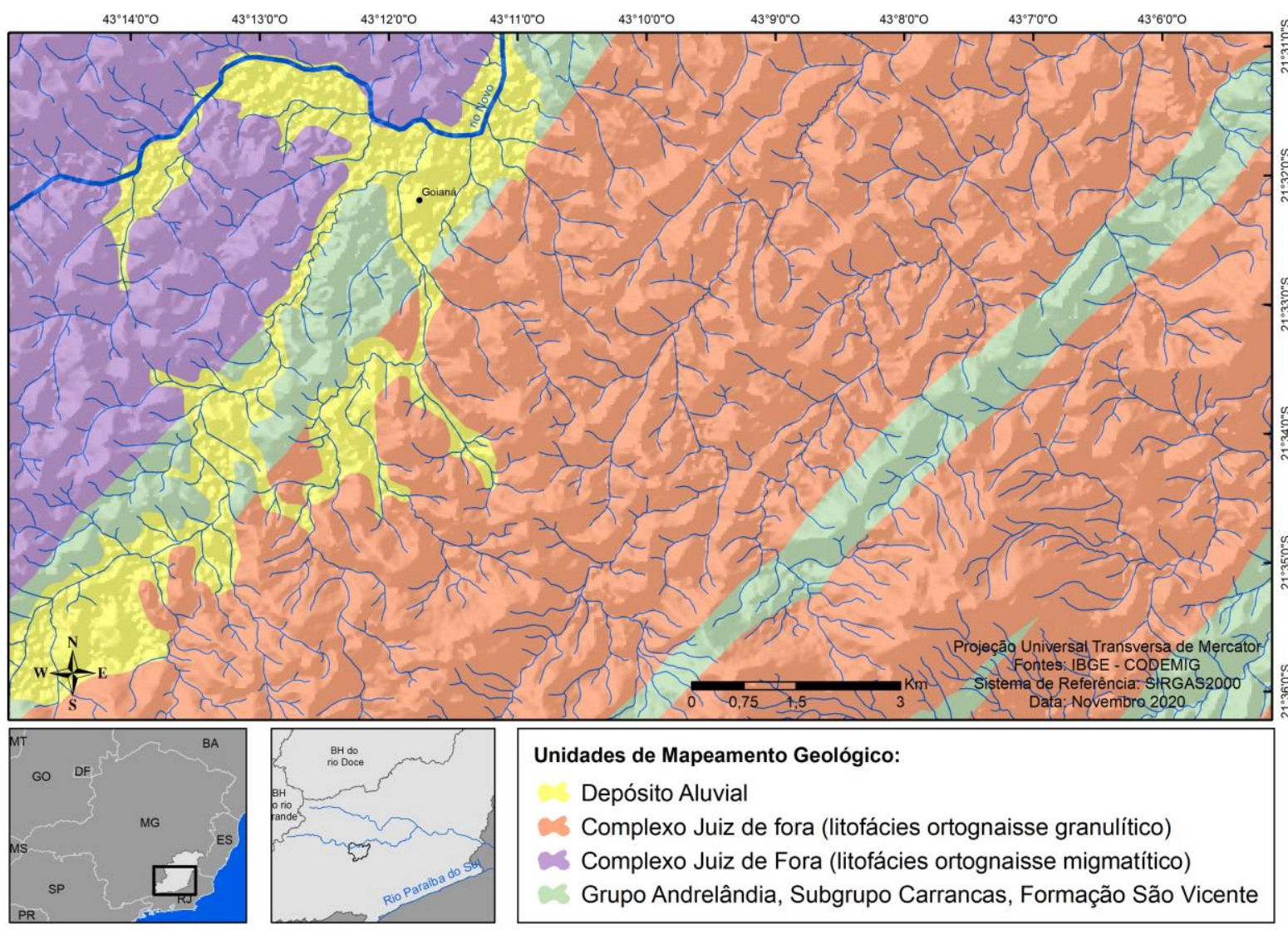

Fonte: Elaborado pelos autores.

\section{MATERIAIS E MÉTODOS}

\section{O método}

Como referencial teórico-metodológico para o alcance dos objetivos vislumbrados, adotou-se a perspectiva sistêmica da realidade, conforme preconizada por Bertalanffy (1973), no domínio das ciências biológicas, e contundentemente contextualizada para o âmbito da ciência geográfica por autores como Chorley e Kennedy (1971) e Christofoletti (1999), visando viabilizar uma análise holística das dinâmicas geomorfológicas inerentes à paisagem do contexto regional ao qual se insere o recorte espacial da presente comunicação. Conforme o entendimento de Bertalanffy (1973), um sistema é, necessariamente, caracterizado por elementos ou unidades que estabelecem relações de dependência entre si através de fluxos de matéria e/ou energia. Esses elementos possuem atributos que Ihes conferem características referentes, por exemplo, à sua composição, comprimento, volume, área ou proporção dos fenômenos intrínsecos. Segundo a perspectiva de Chorley e Kennedy (1971), trata-se de "um conjunto estruturado de objetos e/ou atributos que consistem de componentes ou variáveis que assumem relações discerníveis uns com os outros e operam conjuntamente como um todo complexo, de acordo com determinado padrão".

\section{Concepção metodológica}

A elaboração da carta que espacializa os aspectos geomorfológicos inerentes à paisagem da região, cerne da presente comunicação, teve como parâmetro norteador o sistema metodológico de classificação do relevo concebido pelo Instituto Brasileiro de Geografia e Estatística - IBGE (NUNES

\begin{tabular}{llllll}
\hline Caminhos de Geografia & Uberlândia - MG & v. 22, n. 84 & dez/2021 & p. 215-226 & Página 217
\end{tabular}


et al. 1994), cujo axioma precípuo trata-se do ordenamento dos fatos geomorfológicos em conformidade à uma classificação que pondera aspectos espaciais e temporais, oportunizando o discernimento dos modelados como unidade básica do relevo, assim como os grupamentos os quais estabelecem vínculos hierárquicos com as referidas unidades básicas. Assim, os conjuntos de feições são individualizados mediante aspectos concernentes à sua natureza estrutural, litológica, pedológica, climática e morfodinâmica, aspectos estes compreendidos como variáveis condicionantes da morfogênese, consequentemente influenciando na composição do mosaico paisagístico regional. Dessa forma, em consonância à acepção metodológica retrocitada, em ordem decrescente de grandeza são distintos: Domínios Morfoestruturais, Regiões Geomorfológicas, Unidades Geomorfológicas, Modelados e Formas de Relevo Simbolizadas.

No âmbito do presente paper, o mapeamento geomorfológico partiu do quarto nível categórico proposto por Nunes et al (1994), referente aos tipos de modelados de relevo, o qual forneceu subsídio para a distinção de feições geomorfológicas dotadas de simetrias similares cuja gênese remonta à atuação de processos morfogenéticos comuns, sendo dessa forma identificados dois tipos de modelados distintos partilhando da composição da paisagem. O documento cartográfico ora proposto foi também capaz de abarcar, conforme mencionado, através de simbologias específicas, a representação de feições geomorfológicas condizentes à quinta ordem de grandeza, está representada por feições de proporções espaciais limitadas, como, por exemplo, anomalias de drenagem, meandros abandonados e vales estruturalmente condicionados.

\section{PROCEDIMENTOS}

\section{Aquisição e organização da base de dados}

Os mapas que compõem a presente pesquisa foram confeccionados a partir de técnicas de Geoprocessamento, aplicadas através do software ArcGis10 (ESRI, 2017. A partir da base cartográfica básica do IBGE na escala de 1:50.000 foi realizada a localização da área de estudo. Posteriormente, foi necessário obter-se as cartas do mapeamento topográfico referentes à área. Esse material encontra-se disponível para download a partir do Mapa Índice Digital disponibilizado no site do respectivo instituto de pesquisa. O mapa índice digital trata-se de uma sistematização de todos os dados e informações que o Instituto Brasileiro de Geografia e Estatística (IBGE) e o Exército Brasileiro possuem em seus acervos. No endereço ressaltado encontram-se os documentos que versam sobre a utilização desses dados, bem como os shapefiles produtos do mapeamento digital.

Após adicionar ao software ArcMap (ESRI, 2017) o shape referente ao mapeamento existente é possível identificar quais locais estão cobertos por mapeamentos em variadas escalas. Deve-se então definir a escala condizente ao propósito da pesquisa levada a efeito e verificar se há dados disponíveis sobre a área de interesse na escala em questão. Nesse momento, faz-se necessário discernir as cartas que serão utilizadas para que sejam efetuados seus respectivos downloads. As cartas podem ser identificadas através da tabela de atributos do shape do mapeamento existente do IBGE, através do seu nome ou do índice de nomenclatura. O download dos documentos cartográficos selecionados foi efetuado no endereço do IBGE na internet.

Efetuado o download da carta topográfica selecionada, esta foi adicionada ao ArcMap (ESRI, 2017), ambiente no qual foi executado o seu georreferenciamento. No âmbito da presente pesquisa utilizouse a carta São João Nepomuceno (SF-23-X-D-IV-2), estando a área de interesse localizada no quadrante superior esquerdo, entre as coordenadas UTM N.7620000.7610000; E.682000.696000; Z. $23 \mathrm{~S}$.

A partir da visualização do documento no ambiente do ArcMap (ESRI, 2017), foram selecionados quatro pares de coordenadas geográficas como pontos de controle para o processo de georreferenciamento. Visando-se facilitar o processo de inserção das coordenadas nos documentos cartográficos, foi criada uma planilha eletrônica no Excel contendo os pares ordenados das coordenadas selecionadas, e posteriormente essa tabela foi importada para o ArcGis (File $\rightarrow$ Add File $\rightarrow$ Add $X Y$ data $\rightarrow$ localizar a planilha). Adverte-se aqui que as versões anteriores ao ArcGis10 (ESRI) não possibilitam a importação dessa tabela, tornando impossível esse procedimento.

Nesse momento o software vai solicitar que seja selecionado o sistema de referência a ser adotado no processo de georreferenciamento. É de substancial importância que o sistema selecionado seja condizente com o que a carta foi elaborada, pois, caso não seja, ao se reprojetar essa carta para outro sistema ao qual será desenvolvido o mapeamento haverá a ocorrência de erros. Faz-se 
necessário também alterar o sistema de coordenadas do layer para o mesmo sistema adotado na carta topográfica.

Cumpridos os procedimentos acima descritos partiu-se efetivamente para o georreferenciamento do documento, realizado a partir da ferramenta Georeferencing. Nesse instante abriu-se a tabela de atributos dos pontos de controle previamente selecionados e localizou-se através dos pares ordenados o ponto em questão na carta topográfica a ser georreferenciada. Através da ferramenta denominada Add Control Point clicou-se no ponto a ser referenciado na carta topográfica e selecionou-se, na tabela de atributos dos pontos de controle, a ferramenta Zoom to Selected. A partir dessa ferramenta, clicou-se sobre o ponto correspondente previamente selecionado. Deve-se atentar para a necessidade de o ponto a ser georreferenciado ter de estar selecionado na tabela de atributos. Esse procedimento deve ser repetido para cada um dos pontos de controle previamente escolhidos. Ao finalizar, para salvar o procedimento executado é preciso, na barra de georreferenciamento, clicar em Update Georeferencing.

Conforme anteriormente mencionado, é substancialmente importante que os referidos documentos cartográficos sejam georreferenciados a partir do sistema de referência ao qual foram criados, e este não é condizente com o sistema a ser adotado nessa pesquisa, dessa forma, fez-se necessário reprojetar esse raster. Para isso, utilizou-se a ferramenta denominada Project, disponível no ArcTollBox (ESRI, 2017). Atenta-se para a necessidade de, antes de se aplicar a ferramenta Project, ser criada, através da ferramenta Create Custom Geographic Transformation, também disponível no ArcToolBox, a fórmula para a conversão entre sistemas de referência. Enfatiza-se a importância crucial de se utilizar os parâmetros de transformação entre sistemas geodésicos de referência correspondentes ao sistema em que se encontra o raster (Córrego Alegre) e o sistema ao qual o projeto será desenvolvido, neste caso SIRGAS 2000.

\section{A carta geomorfológica}

Conforme mencionado, o sistema classificatório dos fatos geomorfológicos acolhido para composição da carta geomorfológica aqui proposta foi o de Nunes et al. (1994), desenvolvido no âmbito do IBGE, porém procurando-se, sempre que necessário, realizar adaptações na metodologia, visando que esta se enquadre da melhor forma possível a realidade apresentada pela área de estudo. Assim, a primeira etapa para a elaboração da carta geomorfológica refere-se à leitura, montagem e preparação de banco de dados, análise e interpretação de fontes bibliográficas e cartográficas preexistentes acerca da região, assim como a elaboração e edição de documentos cartográficos que darão subsídio à elaboração da carta geomorfológica.

A carta de declividade (Figura 2), fonte de informação para a classificação das distintas formas de relevo apresentadas pelo mosaico paisagístico, foi composta também a partir do software ArcGis10 (ESRI, 2017), através da ferramenta Slope, tendo como base imagem radar SRTM oriunda de prévio download executado a partir do site da USGS (United States Geological Survey), sendo os intervalos de declividade dispostos conforme a Tabela 1.

Tabela 1 - Classes de Declividade.

\begin{tabular}{cc}
\hline Ordem & Intervalo \\
\hline $\mathbf{1}$ & $<3 \%$ \\
$\mathbf{2}$ & $3-9 \%$ \\
$\mathbf{3}$ & $9-15 \%$ \\
$\mathbf{4}$ & $15-30 \%$ \\
$\mathbf{5}$ & $30-40 \%$ \\
$\mathbf{6}$ & $>45 \%$ \\
\hline
\end{tabular}

Considerando as classes de declividade até $9 \%$ como muito baixas, o arranjo das categorias fica disposto conforme a Tabela 2.

Tabela 2 - Categorias Hierárquicas das Classes de Declividade.

\begin{tabular}{cccccc}
\hline \multicolumn{2}{c}{ Categorias Hierárquicas } & \multicolumn{4}{c}{ Classes de Declividade } \\
\hline \multicolumn{1}{c}{ 1 - Muito fraca } & \multicolumn{4}{c}{ Até 9\% } \\
\hline Caminhos de Geografia & Uberlândia - MG & v. 22, n. 84 & dez/2021 & p. 215-226 & Página 219
\end{tabular}




\begin{tabular}{cc}
\hline 2 - Fraca & $9-15 \%$ \\
3 - Média & $15-30 \%$ \\
4 - Forte & $30-40 \%$ \\
5 - Muito Forte & $>45 \%$ \\
\hline
\end{tabular}

Figura 2 - Carta de Declividade.

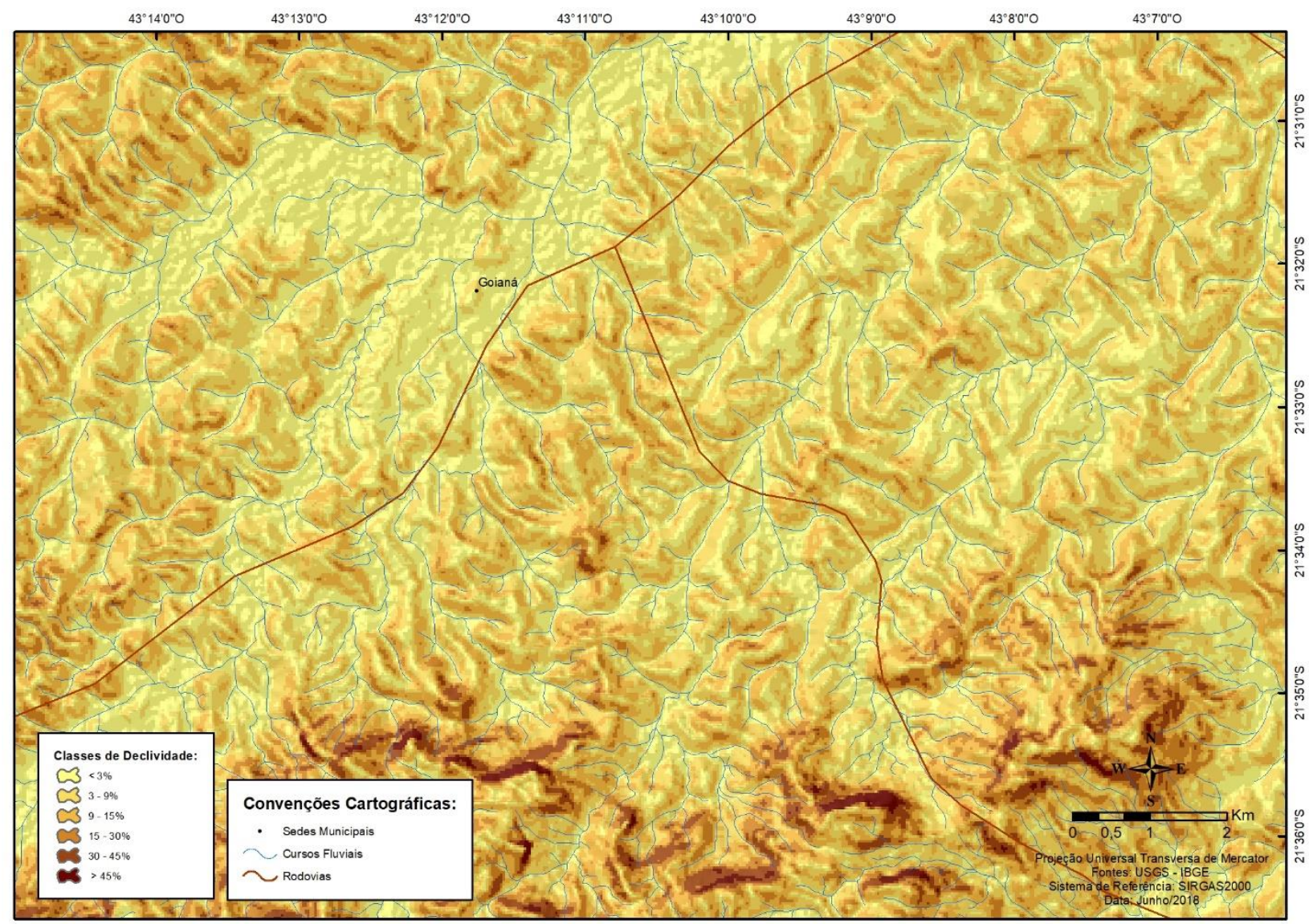

Fonte: Elaborado pelo(s) autor(es).

Para obtenção dos índices morfométricos necessários para individualização dos tipos de modelados de dissecação utilizou-se como base de informação a carta topográfica em escala 1:50.000 do IBGE previamente georreferenciada. Foi criado, a partir do ArcCatalog (ESRI, 2017) um arquivo no formato shapefile de pontos para que, no ArcMap (ESRI, 2017), em sua tabela de atributos, pudessem ser adicionados os valores referentes aos índices morfométricos, no caso a dimensão interfluvial e a profundidade de dissecação, de cada feição geomorfológica de interesse, mantendo assim a devida relação entre o dado e a localização geográfica da feição geomorfológica a qual ele pertence.

A dimensão interfluvial foi obtida a partir da mensuração da extensão da faixa divisória verificável entre as linhas de drenagem posicionadas na base de duas vertentes opostas ou entre duas nascentes. A incisão vertical foi quantificada a partir do estabelecimento da amplitude altimétrica entre os topos e os fundos de vale de referência. As medições mencionadas se deram no plano das Unidades Geomorfológicas (NUNES et.al, 1994), correspondentes à sexta grandeza taxonômica conforme a proposta de Tricart (1965), compreendendo assim todas as geoformas denudacionais existentes no local. A partir desses dados foi possível elaborar a matriz de dissecação, de acordo com a proposta metodológica de Nunes et al. (1994), apropriadamente aplicada por Cunha (2011), sendo esta composta a partir da atribuição de valores de 1 a 5 à profundidade de dissecação e à dimensão interfluvial, conforme ilustra a Tabela 3. Quanto maior for o valor atribuído, mais acentuado é o potencial morfodinâmico da feição de relevo em questão. A partir do cruzamento dos dados obtêm-se um sistema binário que viabiliza a interpretação acerca das características do quadro de fragilidade local. Assim, são obtidas possíveis 25 correlações onde a circunstância 1.1 determina o quadro de fragilidade mais baixo, uma vez que se têm dimensão interfluvial muito grosseira e entalhe vertical muito fraco. Em conjunturas onde se atribuir 5.5, têm-se dimensão interfluvial muito fina e entalhe 
vertical muito forte, denotando um relevo de alta energia (MARQUES NETO; ZAIDAN; MENOR JUNIOR, 2015).

Tabela 3 - Classificação da intensidade dos índices morfométricos.

\begin{tabular}{|c|c|c|c|c|c|}
\hline \multirow{2}{*}{$\begin{array}{l}\text { Intensidade } \\
\text { do entalhe } \\
\text { vertical da } \\
\text { drenagem }\end{array}$} & \multicolumn{5}{|c|}{ Dimensão Interfluvial Média } \\
\hline & $\begin{array}{c}\text { Muito Fina } \\
(<400 \mathrm{~m})\end{array}$ & $\begin{array}{c}\text { Fina (401 a } \\
600 \mathrm{~m})\end{array}$ & $\begin{array}{l}\text { Média } \\
(601 \mathrm{a} \\
800 \mathrm{~m})\end{array}$ & $\begin{array}{c}\text { Grosseira } \\
(801 \mathrm{a} 1000 \mathrm{~m})\end{array}$ & $\begin{array}{c}\text { Muito } \\
\text { Grosseira } \\
(>1000 \mathrm{~m})\end{array}$ \\
\hline $\begin{array}{l}\text { Muito Fraca } \\
\quad(<100 \mathrm{~m}) \\
\text { Fraca }(101 \mathrm{a}\end{array}$ & 5.1 & 4.1 & 3.1 & 2.1 & 1.1 \\
\hline $\begin{array}{c}200 \mathrm{~m}) \\
\text { Mediana }\end{array}$ & 5.2 & 4.2 & 3.2 & 2.2 & 1.2 \\
\hline $\begin{array}{c}(201 \text { a } 500 \mathrm{~m}) \\
\text { Forte }\end{array}$ & 5.3 & 4.3 & 3.3 & 2.3 & 1.3 \\
\hline $\begin{array}{l}(501 \mathrm{a} 1000 \mathrm{~m}) \\
\text { Muito Forte }\end{array}$ & 5.4 & 4.4 & 3.4 & 2.4 & 1.4 \\
\hline$(>1000 \mathrm{~m})$ & 5.5 & 4.5 & 3.5 & 2.5 & 1.5 \\
\hline
\end{tabular}

O reconhecimento e distinção dos conjuntos de formas para elaboração da compartimentação geomorfológica se deu por meio da interpretação de imagens de radar SRTM, sendo estas a base para a delimitação dos distintos padrões morfológicos. A delimitação dos conjuntos de formas foi realizada a partir da interpretação dos elementos texturais da imagem. Essa etapa foi subsidiada pela interpretação conjunta e concomitante da carta topográfica, sendo este procedimento de substancial relevância para propiciar maior precisão no traçado dos padrões de formas. Feito isso, os polígonos discernidos na etapa anterior foram sobrepostos à morfometria para que pudessem ser realizadas possíveis adequações e correções necessárias antes de se proceder a compartimentação final.

Posteriormente foram distintos os modelados de dissecação e de agradação, sendo estes a base para o estabelecimento dos padrões de formas semelhantes em consonância aos níveis taxonômicos de Tricart (1965), adaptados por Ross (1992). Para a execução desse procedimento aplicou-se ao raster com as informações acerca da declividade uma transparência de $70 \%$. Esta foi sobreposta, em ambiente SIG, às cartas topográficas e à morfometria, viabilizando a distinção dos respectivos tipos de modelados e consequentemente sua denominação de acordo com Ponçano et al. (1981). A delimitação dos tipos de modelado segundo os padrões de formas trata-se de um procedimento remetente ao terceiro nível de grandeza têmporo-espacial de Ross (1992). Os parâmetros morfométricos foram representados na legenda em quadro a parte conforme a proposta de Nunes et al. (1994).

Sobre os modelados de dissecação poligonizados foram inseridos símbolos alfanuméricos, adotandose o sistema de letras padrão, iniciado por letra maiúscula que diferencia os modelados de dissecação (D) e agradação (A) e seguido pelas minúsculas específicas às formas de relevo mapeadas. Em associação foram inseridos ao lado das letras os números provenientes da morfometria concernente às morfologias denudacionais previamente quantificadas, conforme ilustra a Figura 3. Essas informações foram indexadas em um campo específico criado na tabela de atributos do shapefile de pontos onde constam as informações referentes aos aspectos morfométricos das geoformas denudacionais em foco.

Figura 3 - Disposição da legenda alfanumérica da carta geomorfológica. 


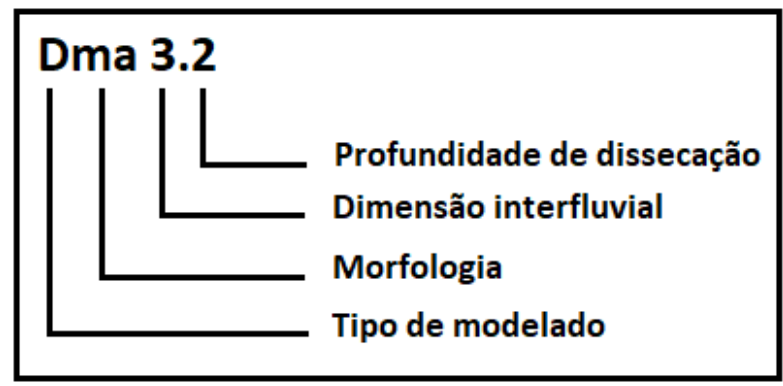

Fonte: Adaptado a partir de Nunes et al. (1994).

Em um segundo nível de abordagem fez-se a inserção de símbolos representativos de feições do relevo e de processos não passiveis de representação na escala trabalhada por meio de polígonos, como por exemplo, meandros abandonados, vales estruturais e anomalias de drenagem, procedimento este que viabiliza a representação de fatos geomorfológicos individuais em sua forma e extensão. Para tanto, foi criado um shapefile de pontos para cada tipo de morfologia discernida, a ser representada por simbologia pontual; para os aspectos a serem representados de forma linear, um shapefile do tipo linha também foi estabelecido.

O produto cartográfico final foi digitalizado em software ArcGis 10.5.1 (ESRI, 2017), apresentando-se o mapa e a legenda em figuras separadas em função do grande número de informações inerentes ao corpo da legenda, procedimento que tem por finalidade facilitar a leitura da mesma, constituída por associações de cores, recursos textuais, códigos alfanuméricos e demais simbologias que permitem uma compatibilização entre os níveis taxonômicos e as feições geomórficas de mapeamento exequível.

Concomitante à sequência de procedimentos cartográficos anteriormente mencionados foram realizadas incursões a campo para reconhecimento e interpretação do relevo, sendo estas de substancial importância para o mapeamento, bem como para embasar uma discussão plausível acerca do quadro geomorfológico local, pautada no reconhecimento de formas, processos e coberturas superficiais.

\section{RESULTADOS E DISCUSSÕES}

A partir da adoção como concepção metodológica do sistema classificatório dos fatos geomorfológicos elaborado no âmbito do IBGE (NUNES et al.1994) foi exequível o reconhecimento de dois distintos tipos de modelado de relevo na região do município de Goianá, na Zona da Mata Mineira, sendo estes a fundamentação para a definição dos padrões de formas semelhantes em conformidade aos níveis taxonômicos de Tricart (1965). Seguindo as prescrições dos autores supracitados, apresenta-se a seguir a carta geomorfológica (Figura 4) fruto da aplicação metodológica anteriormente explanada, sendo sua legenda disposta em figura a parte (Figura 5), com intuito de facilitar sua leitura, tendo em vista o grau de detalhamento inerente à mesma, e ulteriormente sua respectiva apreciação.

Integralizando os modelados de dissecação, na área de cobertura foram identificados nove distintos padrões de formas de relevo: colinas (Dc), morrotes (Dmr), morros alongados (Dma), morros estruturais (Dme), morros profundamente dissecados (Dmpd), morros interfluviais alongados (Dmia), patamares reafeiçoados (Dpr) e cristas estruturais dissecadas (Dced).

As colinas (Dc) figuram na área de estudo como feições de proporções variáveis, cujas dimensões interfluviais oscilam entre 401 a 600 metros, conforme Nunes et al. (1994), classificando-as como fina, e profundidade de dissecação inferior a 100 metros, o que denota um quadro de baixa fragilidade ambiental. Encontram-se amplamente difundidas ao longo da área de estudo, tendo sua ocorrência associada aos fundos de vales do rio Novo e seus principais afluentes no local, bem como vinculadas a morros e setores de relevo montanhoso. Associadas às colinas, ocasionalmente, tem-se morrotes (Dmr), tratando-se estes de morfologias rebaixadas cuja gênese remonta ao intensificado processo de dissecação do relevo ao qual a região esteve submetida durante o período Quaternário. As altitudes médias dos morrotes e colinas estão compreendidas entre 350 e 500 metros acima do nível oceânico, aproximadamente. Os morrotes possuem dimensão interfluvial média variando entre 401 a 800 metros, classificadas, conforme Nunes et al. (1994) como fina a média e profundidade de dissecação muito fina ( $>400$ metros). 
Os morros configuram típicas morfologias mamelonares de mesma origem genética que os morrotes e as colinas, porém com evolução distinta marcada por maior dissecação mais densa e maior entalhe vertical. Os morros alongados (Dma) e os morros interfluviais alongados (Dmia), em prevalência, possuem dimensão interfluvial variando de 400 a 600 metros, o que configura dimensão interfluvial muito fina a fina e profundidade de dissecação muito fraca ( $<100$ metros) a fraca (101 a 200 metros) (NUNES et al., 1994). Os morros estruturais (Dme) foram assim classificados por possuírem em sua gênese notável influência dos aspectos estruturais inerentes à região. Quanto aos morros profundamente dissecados (Dmpd), estes possuem dimensão interfluvial similar à das morfologias acima descritas, diferenciando-se destas por serem dotadas de profundidade de dissecação mediana (201 a 500 metros) (NUNES et al., 1994). Os morros possuem altitude média compreendida entre 500 e 600 metros. Os índices morfométricos dos morros indicam, assim como no caso das colinas e morrotes, que essas morfologias apresentam um baixo grau de fragilidade ambiental, característica que eclode sempre que forem respeitadas as singularidades ambientais e restrições de uso e ocupação apresentadas por cada contexto em questão.

Ainda no âmbito das geoformas cuja gênese remonta aos processos de dissecação atuantes na região em voga foram também identificadas morfologias de tipicidade montanhosa. Denominada crista estrutural dissecada (Dced), trata-se de uma serra alongada, sob influência de controle estrutural no sentido NE/SW, decorrente dos esforços compressionais exercidos pelo Rift Continental do Sudeste Brasileiro (RICCOMINI,1989), caracterizadas pela presença de cristas e vales estruturalmente condicionados. A referida feição geomorfológica encontra-se a sudeste da sede municipal de Goianá, apresentando altitude compreendida entre 900 e 1000 metros. As morfologias da Serra de Santana possuem dimensão interfluvial fina, variando entre 401 e 600 metros, e profundidade do entalhe fluvial mediana, compreendida entre 201 e 500 metros (NUNES et al.1994), apresentando um contexto de fragilidade ambiental um pouco mais agudo quando comparado ao apresentado pelas demais geoformas denudacionais componentes do mosaico paisagístico compreendido na área de interesse.

Integralizando os modelados de relevo os quais seu engendramento remonta aos processos de acumulação sedimentar, foram classificados quatro categorias de planícies fluviais: (1) As planícies fluvio-lacustres antropogênicas (Apfla), que tem sua gênese associada aos processos de acumulação fluvial e lacustre antropogênica, sendo sujeitas a inundações periódicas e com barramentos, formando lagos; (2) As planícies altimontanas (Apat), áreas relativamente planas, resultantes da acumulação fluvial, com depósitos aluviais quaternários descontínuos em altitude; (3) As planícies alveolares (Apav), áreas relativamente planas, descontínuas, restritas em alvéolos, recobertos por depósitos quaternários em altitude; e (4) Planícies fluviais associadas a terraços (Apft), que têm sua ocorrência circunscrita aos vales com preenchimento aluvial, contendo material fino a grosseiro, pleistocênico e holocênico. São identificados em conjuntos devido à limitação de representação nesta escala de mapeamento. 


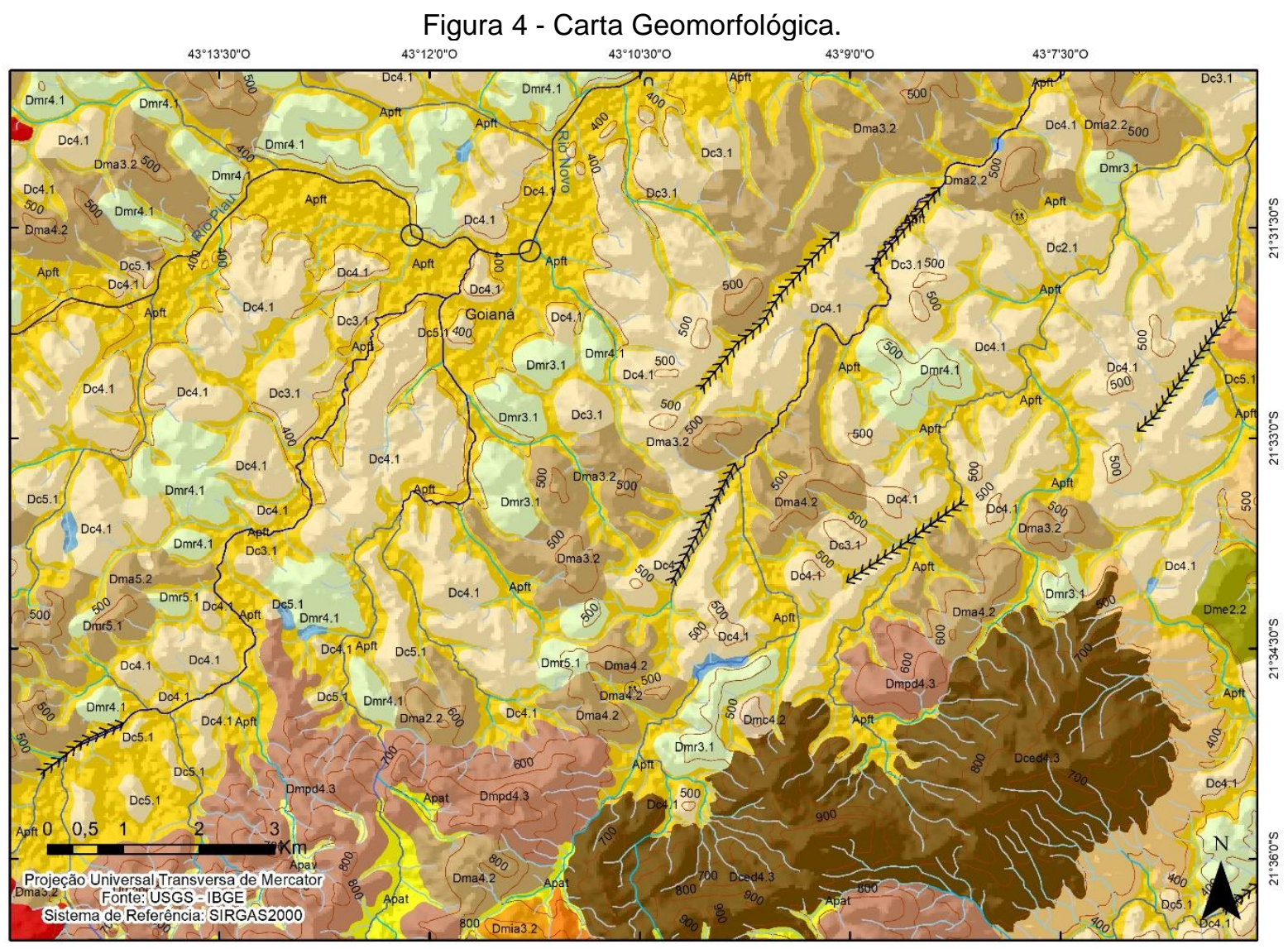

Fonte: Elaborado pelo(s) autor(es).

Figura 5 - Legenda da carta geomorfológica.

MODELADOS DE AGRADAÇÂO (A):

PLANICIES FLUVIO LACUSTRES ANTROPOGÊNICAS (Aptla): Áreas planas resultantes de processos de acunulação fluvial e lacustre antropogenica, podendo comportar canais anastomosados, paleomeandros e diques marginais. Ocorre em setores sob etento de processos combinados de acumulaçăo fluvivi o

Processos antropogenicos suj TERRACOS (A pfr): Áreas planas resultantes de acumulaçào fluvial, periodicamente alagadas, comportando meandros abandonados e cordoes arenosos. Ocorrem nos vales com preenchimento aluvial. contendo material fino a grosseiro, pleistocènico e holocênico. Săo identificados em conjuntos devido à limitaçăo de representaçào nesta escala de mapeamlento.

PLANiCIES ALTIMONTANAS (Apat): Ȧreas relativamente planas, resultantes da acumulaçăo fluvial, com depositos altuviais quatemánios desconiminos ent altitude

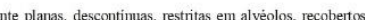
por depósitos quatemários em altitude.

\section{MODELADOS DE DISSECAÇÃO (D):}

COLINAS (Dc): Feiçỏes de tamanho e largura variável. Ocorrem vinculadas ao morros e setores de relevo montanhoso, comportando materiais de granulometria arenosa c argilosa, transicionam o dominio das encostas com os

MORROS ALONGADOS (Dma): Morfologias mamelonares quaternarias com fommato alongado. MORROS PROFUNDAMENTE DISSECADOS (Dmpd): Morfologias mamelonares quaternárias profiundamente

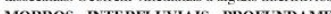

DISSECADOS (Dmipd): Morfologias mamelonares viais profundamente dissecadas.

YORROS INTERFLIVLISS ALONGADOS (Dmia): Morfologias mamelonares guaternárias alongades

PATAMARES REAFEICCOADOS (Dpr): Patamares de relevo reafeiçoados pelo intenso processo de dissecaç̧o

CRISTAS ESTRUTURAIS DISSECADAS (Dced): Conjunto de morfologias composto por serras e/ou conjumtos de serras alongadas. sob influência de controle estuturual. caracterizada pela presença de cristas e vales estruturais.

\begin{tabular}{|c|c|c|c|c|c|}
\hline \multicolumn{6}{|c|}{ Modelados de Agradação (A): } \\
\hline Aplla & & Apft & $\mathbf{A p}$ & & Apav \\
\hline \multicolumn{6}{|c|}{ Modelados de Dissecação (D): } \\
\hline & \multicolumn{2}{|c|}{ Dme } & \multicolumn{2}{|c|}{ Dmpd } \\
\hline \multicolumn{2}{|c|}{$\begin{array}{l}\text { Dmr } \\
\text { Dma }\end{array}$} & \multicolumn{2}{|c|}{$\begin{array}{c}\text { Dmia } \\
\text { Dmipd }\end{array}$} & \multicolumn{2}{|c|}{$\begin{array}{c}\text { Dpr } \\
\text { Deed }\end{array}$} \\
\hline$\stackrel{\substack{n \\
0}}{R}$ & $\begin{array}{l}\text { Meandros Aba } \\
\text { Anomalias de } \\
\text { Vales Estrutur } \\
\text { Alinhamento S } \\
\text { Curvas Mestra }\end{array}$ & $\begin{array}{l}\text { ado: } \\
\text { lonados } \\
\text { enagem } \\
\text { rano }\end{array}$ & 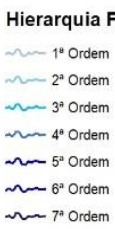 & Ivial (Strahle & 1952): \\
\hline \multicolumn{6}{|c|}{ MORFOMETRIA DOS MODELADOS DE DISSECACYĀO } \\
\hline \multirow{2}{*}{$\begin{array}{l}\text { Intensidade do } \\
\text { entalhe vertical } \\
\text { da drenagem }\end{array}$} & \multicolumn{5}{|c|}{ Dimensào Interfluvial Média } \\
\hline & $\begin{array}{c}\begin{array}{c}\text { Muito Fina } \\
(<400 \mathrm{~m})\end{array} \\
\end{array}$ & $\begin{array}{c}\text { Fina } \\
(401 \mathrm{a} 600 \mathrm{~m})\end{array}$ & $\begin{array}{c}\text { Mélia } \\
\text { (601 a } 800 \mathrm{~m})\end{array}$ & $\begin{array}{c}\text { Grosseira } \\
\text { (801a1000m) }\end{array}$ & $\begin{array}{c}\text { Muito } \\
\text { Grosseira } \\
(>1000 \mathrm{~m})\end{array}$ \\
\hline $\begin{array}{c}\text { Muito Fraca } \\
(<100 \mathrm{~m})\end{array}$ & 5.1 & 4.1 & 3.1 & 2.1 & 1.1 \\
\hline $\begin{array}{c}\text { Fraca } \\
(101 \text { a 200m })\end{array}$ & 5.2 & 4.2 & 3.2 & 2.2 & 1.2 \\
\hline $\begin{array}{l}\text { Mediana (201 a } \\
500 \mathrm{~m})\end{array}$ & 5.3 & 4.3 & 3.3 & 2.3 & 1.3 \\
\hline $\begin{array}{c}\text { Forte } \\
\text { (501a1000m) }\end{array}$ & 5.4 & 4.4 & 3.4 & 2.4 & 1.4 \\
\hline $\begin{array}{c}\text { Muito Forte } \\
(>1000 \mathrm{~m})\end{array}$ & 5.5 & 4.5 & 3.5 & 2.5 & 1.5 \\
\hline
\end{tabular}

Fonte: Elaborado pelo(s) autor(es).

\section{ASPECTOS CONCLUSIVOS}

O sistema classificatório dos fatos geomorfológicos empregado no âmbito da presente experiência de mapeamento, e consequentemente na interpretação das formas e processos atuantes, demonstrouse devidamente congruente com os objetivos ora ambicionados, ensejando a composição de um \begin{tabular}{llllll}
\hline Caminhos de Geografia & Uberlândia - MG & v. 22, n. 84 & dez/2021 & p. 215-226 & Página 224
\end{tabular} 
documento cartográfico que assegura o cumprimento das determinações técnicas para a caracterização do mesmo. A carta geomorfológica gerada apresenta aspectos referentes às informações morfográficas, morfogenéticas, morfométricas e morfocronológicas, para isso usufruindo de diferentes táticas, a exemplo, a utilização de simbologias lineares e pontuais para espacialização de feições e aspectos do relevo impassíveis de serem poligonizados devido a restrições impostas pela escala adotada. Cabe aqui salientar a pertinência dos esforços em prol da estruturação de adequações metodológicas no âmbito da cartografia geomorfológica, tendo em vista a inaplicabilidade perfeita de uma metodologia desenvolvida para um determinado contexto geoambiental em outro distinto.

Tendo em vista a complexidade do trato cartográfico do relevo, uma vez que se enseja a representação de atributos de natureza tridimensional dispondo-se de um plano bidimensional, o geoprocessamento mostrou-se uma salutar, precisa e confiável ferramenta metodológica, facilitando e agilizando o processo de mapeamento. O software ArcGis 10.5.1 (ESRI, 2017) possib ilitou a produção, manipulação, cruzamento e análise de uma ampla gama de dados georreferenciados e informações acerca da área de estudo, corroborando na concepção de um produto cartográfico preciso e de boa qualidade capaz de subsidiar de forma significativa a tomada de decisão acerca da disposição dos diferentes tipos de ocupação e uso econômico da terra, em consonância com as possibilidades e restrições impostas pelos condicionantes geomorfológicos regionais.

O uso do software ArcGis 10.5.1 (ESRI, 2017) configurou-se como um grande facilitador em alguns momentos específicos do desenrolar do processo metodológico, como por exemplo na fase de levantamento dos índices morfométricos, uma vez que o programa possibilita que essas informações possam ser obtidas de forma direta, ou seja, sem demandar a conversão do valor a partir da escala da carta topográfica. Outro facilitador nessa fase do mapeamento proporcionado pelo ArcGis10 10.5.1 (ESRI, 2017) foi a possibilidade de organizar essas informações a partir da tabela de atributos de um shapefile de pontos, mantendo assim a devida congruência entre o dado e a localização geográfica da feição geomorfológica a qual ele pertence. O software mostrou-se também bastante funcional no que tange à sobreposição de bases de informação, possibilitando um cruzamento preciso das informações a serem consideradas para a execução do mapeamento proposto.

\section{REFERÊNCIAS}

BERTALANFFY, L. V. Teoria Geral dos Sistemas. Rio de Janeiro: Vozes, 1973. 351 p.

CÂMARA, G. et al. Anatomia de Sistemas de Informação Geográfica. Campinas: Instituto de Computação, UNICAMP, 1996. 193p.

CHORLEY, R. J.; KENNEDY, B. A. Physical Geography: a systems approach. London: Prentice Hall, 1971.

CHRISTOFOLETTI, A. Modelagem de Sistemas Ambientais. 1‥ ed. São Paulo: Edgard Blucher, 1999. $256 \mathrm{p}$.

COLTRINARI, L. Cartografia Geomorfológica detalhada: A representação gráfica do relevo entre 1950-1970. Revista Brasileira de Geomorfologia, v.12, n3, p121-130,2011. Disponível em: < http://www.lsie.unb.br/rbg/index.php/rbg/article/view/265 > Acesso em: 20 nov. 2020.

CUNHA, C. M. L. Cartografia Geomorfológica em áreas litorâneas, 2011. Tese (Doutorado em Geomorfologia) - Departamento de Geociências, Universidade Estadual Paulista Júlio de Mesquita Filho, Rio Claro, São Paulo.

ESRI - Environmental Systems Research Institute. ArcGIS 10.5.1. Disponível em: http://www.esri.com/software/ arcgis/explorer/index.html. Acesso em: 20 nov 2020.

FLORENZANO, T. G. (org.). Geomorfologia: conceitos e tecnologias atuais. São Paulo: Oficina de Textos, 2008.

IBGE - Instituto Brasileiro de Geografia e Estatística. São João Nepomuceno: região sudeste do Brasil. 1. ed. Rio de Janeiro: IBGE, 1976. 1 carta topográfica, color., $4465 \times 3555$ pixels, 5,50 MB, jpeg. Escala 1:50.000. Projeção UTM. Datum horizontal: marégrafo Imbituba, SC, Datum vertical: Córrego Alegre, MG. Folha SF 23-Y-A-VI-1, MI 2738-1. Disponível em: http://biblioteca. ibge.gov.br/index.php/biblioteca-catalogo?view=detalhes\&id=6401. Acesso em: 20 nov. 2020. 
MARQUES NETO, R., ZAIDAN, R. T., MENOR JUNIOR, W. Mapeamento Geomorfológico do Município de Lima Duarte (MG). Revista Brasileira de Geomorfologia, São Paulo, v.16, n.1, p.123136, jan./mar. 2015. Disponível em: < http://www.lsie.unb.br/rbg/index.php/rbg/article/view/641 > Acesso em: 20 nov. 2020.

NUNES, B. A.; RIBEIRO, M. I de C.; ALMEIDA, V. J.; NATALI FILHO, T. Manual técnico de geomorfologia. Rio de Janeiro: IBGE, 1994. 113p. (Série Manuais Técnicos em Geociências, n.5). PINTO C. P.; SILVA M. A. Mapa Geológico do Estado de Minas Gerais. CODEMIG/CPRM, 2014. PONÇANO, W. L; CARNEIRO, C. D. R; BISTRICHI, C. A; ALMEIDA, F. F. M; PRANDINI, F. L. Mapa geomorfológico do estado de São Paulo. Vol. 1. Instituto de Pesquisas Tecnológicas, Divisão de Minas e Geologia Aplicada, 1981. 94p.

RICCOMINI, C. O Rift Continental do Sudeste do Brasil. 1989. 319 f. Tese (Doutorado em Geologia) - Programa de Pós-Graduação em Geologia Sedimentar, [S. I.], 1989. Disponível em: < http://www.teses.usp.br/teses/disponiveis/44/44136/tde-18032013-105507/pt-br.php > Acesso em: 20 nov. 2020.

RODRIGUES, S. C. Cartografia e simbologia geomorfológica: Evoluindo da cartografia tradicional para o uso de simbologia digital. Revista Brasileira de Geomorfologia, São Paulo, v.11, n.1, p.0310, Jan/Jun, 2010. Disponível em: <http://www.lsie.unb.br/rbg/index.php/rbg/article/view/136/130> Acesso em: 20 nov. 2020.

ROSS, J. L. S. O registro cartográfico dos fatos geomórficos e a questão da taxonomia do relevo. Revista do Departamento de Geografia, São Paulo, FFLCH - USP, n.6, 1992. Disponível em: $<$ http://www.revistas.usp.br/rdg/article/view/47108 > Acesso em: 20 nov. 2020.

TRICART, J. Principes et méthodes de I geomorphologie. Paris: Masson Ed., 1965.

USGS - United States Geological Survey. Imagem radar SRTM - Shuttle Radar Topographic Mission. Disponível em: < https://earthexplorer.usgs.gov/>. Acesso em: 20 de Nov. 2020.

Recebido em: 29/08/2020

Aceito para publicação em: 22/12/2020 